\title{
FULL PAPER \\ Effect of QSOX1 on cattle carcass traits as well as apoptosis and triglyceride production in bovine fetal fibroblasts and mammary epithelial cells
}

\author{
Xiaochuan LIU1), Yuwei YANG ${ }^{1)}$, Ping JIANG ${ }^{1)}$, Xiaohui LI'), Yanliang GE'), \\ Yang $\mathrm{CAO}^{2)}$, Zhihui $\mathrm{ZHAO}^{3)}$, Xibi FANG ${ }^{1) *}$ and Xianzhong $\mathrm{YU}^{1,4) *}$ \\ ${ }^{1)}$ College of Animal Science, Jilin University, Xi An Road 5333, Changchun, Jilin 130062, P.R. China \\ ${ }^{2)}$ Branch of Animal Husbandry, Jilin Academy of Agricultural Sciences, Changchun 130033, P.R. China \\ ${ }^{3)}$ Agricultural College, Guangdong Ocean University, Zhanjiang 524088, P.R. China \\ ${ }^{4)}$ Department of Biological Sciences, 132 Long Hall, Clemson University, Clemson, SC 29634, U.S.A.
}

J. Vet. Med. Sci.

80(8): 1329-1336, 2018

doi: 10.1292/jvms.17-0705

Received: 27 December 2017

Accepted: 24 May 2018

Published online in J-STAGE:

30 May 2018
ABSTRACT. QSOX1 (quiescin-sulfhydryl oxidase 1) is involved in various processes, including apoptosis and the development of breast diseases. Here, we investigated the effect of QSOX1 on the meat quality of Simmental cattle by analyzing the correlation between QSOX1 single nucleotide polymorphisms (SNPs), I2 $204 \mathrm{C}>\mathrm{T}$ and I2 $378 \mathrm{C}>\mathrm{T}$, and certain meat quality traits. The effects of QSOX1 on triglyceride synthesis and cell apoptosis were further validated by gene silencing or overexpression in bovine fetal fibroblasts and mammary epithelial cells. The results showed that I2 204 C > T and I2 378 C > T had significant correlations with loin thickness, hind hoof weight, fat coverage, liver weight, heart weight, marbling and back fat thickness $(P<0.05)$. QSOX1 overexpression also increased triglyceride production and suppressed apoptosis. In summary, QSOX1 is an important factor for meat quality, lipid metabolism, and cell apoptosis, indicating that QSOX1 could be used as a biomarker to assist in breeding cattle with superior meat.

KEY WORDS: apoptosis, carcass traits, QSOX1, SNPs, triglyceride

With the rapid advancement of molecular genetics, high quality offspring with excellent meat qualities are being chosen using gene marker-assisted selection (MAS) programs including higher slaughter rates, proper ratio of fat, and better testicular development $[10,18,19]$.

Quiescin-sulfhydryl oxidase 1 (QSOX1) is an important enzyme for the formation of disulfide bonds, which are critical for protein folding and stability $[15,16]$. QSOX1 is located on chromosome 16 in cattle; has 13 exons; is homologous in humans, mice, rats, chickens, and seven other species; and encodes a protein containing 567 amino acid residues. The amino acid residues 41 to 153 and 407 to 502, respectively, encode the domains of thioredoxin and ERV1 [6, 13], members of two longstanding gene families. Recently, QSOX1 was found to be involved in various biological processes including viral replication, embryonic development, inflammation, and cancer. The structural integrity of the soluble dimeric prion protein was shown to be significantly correlated with $Q S O X 1$, and the protein can therefore be obtained in bacteria by co-expression of human $Q S O X[1]$. Overexpression of $Q S O X 1$ ensures the complete development of the placenta and normal embryos [14]. The overexpression of QSOX1 in alveolar type II cells indicates that QSOX1 plays important roles in the prevention of inflammation and fibrogenesis in lung inflammatory diseases [17]. QSOX1 is overexpressed in diverse tumor types and hence, might be involved in promoting the growth and invasion of tumor cells and altering the composition of the extracellular matrix [11]. It was suggested that QSOX1 could be a biomarker for identifying individuals with higher risk for certain types of cancer, including neural tumors, pancreatic cancer, and breast cancer $[2,8,12]$. Site-directed mutagenesis suggested that the C449-C452 motif is essential for the activity of QSOX1; the C70-C73 motif is fundamental in the transfer of electrons from thiol-containing substrates, including the reduced proteins DTT (DL-Dithiothreitol) and GSH (glutathione), to the C449-C452 motif; and the C509-C512 motif is not involved in electron transfer during disulphide formation [20]. QSOX1 is significantly differentially expressed between high- and low-fat dairy cows, suggesting that it might be correlated with meat quality [7].

Therefore, $Q S O X 1$ might be a new factor that regulates meat quality traits, apoptosis, and triglyceride production. In the present study, the association of QSOX1 I2 $204 \mathrm{C}>\mathrm{T}$ and $\mathrm{I} 2378 \mathrm{C}>\mathrm{T}$ with cattle carcass traits was analyzed. We then transfected

*Correspondence to: Fang, X.: fangxibi@jlu.edu.cn,Yu, X.: xyu@clemson.edu

O2018 The Japanese Society of Veterinary Science

This is an open-access article distributed under the terms of the Creative Commons Attribution Non-Commercial No Derivatives (by-nc-nd) License. (CC-BY-NC-ND 4.0: https://creativecommons.org/licenses/by-nc-nd/4.o/) 
an overexpression vector and a silencing vector of QSOX1 into bovine fetal fibroblasts (BFFs) and mammary epithelial cells (MECs) and verified their effects on cell apoptosis and triglyceride production.

\section{MATERIALS AND METHODS}

\section{Ethics statement}

This study involved 350 Chinese Simmental steers (28 months old) from cattle farm Inner Mongolian Baolongshan. These cattle were randomly selected from the offspring of a Simmental population comprising approximately 2,000 cows and 25 bulls. Blood samples ( $10 \mathrm{~m} l$ each) were collected with anticoagulant (acid citrate dextrose, ACD) from the jugular vein and stored at $-70^{\circ} \mathrm{C}$. Animal experiments were performed in strict accordance with the guidance for the care and use of laboratory animals by the Jilin University Animal Care and Use Committee (Permit number: SYXK (Ji) 2008-0010/0011). Carcass and meat qualities were measured according to the instructions of the Chinese Academy of Agricultural Sciences Meat Laboratory.

\section{DNA extraction and PCR amplification}

Genomic DNA was extracted from $1 \mathrm{~m} l$ cattle blood, using the DNA extraction kit (Tiangen, Beijing, China). The purity of DNA was evaluated using agarose gel electrophoresis. The second intron fragment of QSOX1 was amplified from genomic DNA, using primers designed with primer premier 5.0 software according to the published sequence on the NCBI website (Gene ID: 522986) (Table 1). The primers were synthesized by the Shanghai Biological Company. The PCR conditions for QSOX1 amplification were an initial denaturing step at $95^{\circ} \mathrm{C}$ for $5 \mathrm{~min}$, followed by 30 cycles of $95^{\circ} \mathrm{C}$ for $5 \mathrm{sec}, 60^{\circ} \mathrm{C}$ for $30 \mathrm{sec}$ and $72^{\circ} \mathrm{C}$ for $45 \mathrm{sec}$, with a final extension step at $72^{\circ} \mathrm{C}$ for $10 \mathrm{~min}$.

\section{SNP detection and genotyping}

Two polymorphisms of $Q S O X 1$ were identified by sequencing and confirmed by PCR-RFLP, using restriction enzymes (BsaHI for I2 $204 \mathrm{C}>\mathrm{T}$ digestion and AvaI for I2 $378 \mathrm{C}>\mathrm{T}$ identification) in the second intron.

\section{Vector construction}

For gene knockdown, BFFs and MECs were transfected with shRNA vectors of Neo-shNC, Neo-QSOX1-bos-374, Neo-QSOX1bos-1667, Neo-QSOX1-bos-1057 and Neo-QSOX1-bos-737 purchased from the Zimmer Biotechnology Company. For gene

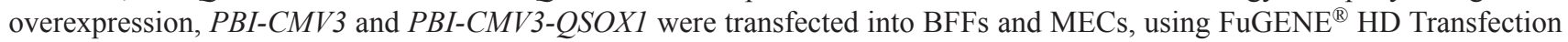
Reagent (Promega, Madison, WI, U.S.A.).

\section{Cell lines and cell transfection}

Bovine MECs and BFFs were obtained from the laboratory of animal genetics at Jilin University. Twenty-four hours before transfection, the BFFs and MECs were plated at a concentration of approximately $1 \times 10^{6} /$ well into six-well culture plates with DMEM/F12 (GIBCO, Grand Island, NY, U.S.A.) containing 10\% fetal bovine serum (FBS; PAA, Pasching, Austria) and 1\% penicillin-streptomycin. To investigate the regulation role of $Q S O X 1$ on apoptosis and triglyceride production in cells, $150 \mu l$ Opti-MEM serum-free medium (GIBCO) was mixed with $5 \mu l$ of Lipofectamine TM 2000 (Invitrogen, Carlsbad, CA, U.S.A.) and $1.25 \mu \mathrm{l}$ (of $20 \mu \mathrm{mol}$ concentrations) each of the silencing vector Neo-QSOX1-bos-1667, overexpression vector PBI-CMV3-QSOX1, and negative control Neo-shNC, PBI-CMV3. Then, cells were incubated in Opti-MEM serum-free medium at room temperature for $30 \mathrm{~min}$, after which the transfection mixture was added to each well. The medium was replaced with regular cell culture medium after 3-5 hr. After $48 \mathrm{hr}$ of transfection, the cell morphology and expression level of green fluorescent protein were observed under a fluorescence microscope (NikonTE2000, Tokyo, Japan) to determine the transfection efficiency. The total RNA and protein were obtained for expression analyzes.

\section{Quantitative real-time polymerase chain reaction ( $q P C R$ )}

After $48 \mathrm{hr}$ of transfection, total RNA was extracted from the cultured cells and cDNA was synthesized using a cDNA synthesis kit according to the manufacturer's protocol (TaKaRa Biotechnology, Dalian, China). PCR amplification was performed in $20 \mu l$ reaction volumes under the following conditions: an initial denaturing step at $95^{\circ} \mathrm{C}$ for $30 \mathrm{sec}$, followed by 40 cycles of $95^{\circ} \mathrm{C}$ for $5 \mathrm{sec}$ and $60^{\circ} \mathrm{C}$ for $30 \mathrm{sec}$ (Table 1). Different samples were adjusted to the same concentration, and each sample was repeated three times. The data were analyzed using SPSS 19.0 software, and the fold change of expression was calculated using the $2^{-\Delta \Delta C T}$ method according to the following formula:

$\Delta \Delta \mathrm{Ct}=[\mathrm{Ct}$ (positive) $-\mathrm{Ct}$ (reference) $]-[\mathrm{Ct}$ (control) $-\mathrm{Ct}$ (reference) $]$, where $2^{-\Delta \Delta \mathrm{Ct}}$ refers to the relative expression ratio.

\section{Western blot analysis}

After $48 \mathrm{hr}$ of transfection, total protein was extracted using the RIPA buffer (Boster, Wuhan, China) following the manufacturer's instructions. The BCA Protein Assay Kit (Boster, Wuhan, China) was used for protein quantification; the 
concentrations in different groups were adjusted to the same concentration, and each sample was repeated three times. The western blot analysis was performed according to previously published protocols, using anti-QSOX1 antibody diluted as suggested by the manufacturer (Abcam, Shanghai, China) [3].

\section{Cell apoptosis analysis by flow cytometery}

After $48 \mathrm{hr}$ of transfection, the MECs and BFFs transfected with Neo-QSOX1-bos-1667, PBI-CMV3-QSOX1, and Neo-shNC, $P B I-C M V 3$ were harvested and washed twice with PBS. Then, three blank samples were used to to adjust the differences between the groups, using the Apoptosis Detection Kit for reference (KeyGEN BioTECH, Nanjing, China). Then, the cells were processed using the Apoptosis Detection Kit according to the instructions and analyzed by flow cytometry (BD Biosciences, San Jose, CA, U.S.A.) to verify the effects of $Q S O X 1$ on cell apoptosis.

\section{Triglyceride detection}

After $48 \mathrm{hr}$ of transfection, triglycerides were detected using the total cell lysate from each of the transfected cells, following the manufacturer's instructions (Applygen, Beijing, China) and using a SpectraMax M5 Microplate Reader (Molecular Devices, Sunnyvale, CA, U.S.A.). The cellular content of TG was adjusted based on the quantity of protein, and each group was repeated three times. The calculation of TG was based on the following formula: TG content $(\mu \mathrm{mol} / \mathrm{g})=$ triglyceride concentration $(\mu \mathrm{mol} / l) /$ total protein concentration $(\mathrm{mg} / \mathrm{ml})$.

\section{Statistical analysis}

SPSS 19.0 was used to analyze the association between the genotypes of QSOX1 (I2 $204 \mathrm{C}>\mathrm{T}$ and I2 $378 \mathrm{C}>\mathrm{T}$ ) and the slaughter and meat quality traits of Simmental cattle. The fixed model was referring to previous research in our laboratory [10]. The expression levels of QSOX1 mRNA and protein and the effects of QSOX1 on apoptosis and triglyceride production were analyzed using GraphPad Software with a two-tailed $t$-test (unpaired $t$-test) between two groups. The means and standard deviation of triplicates were calculated, and then the $P$ values of the groups were determined for the differential expression analysis. Statistically significant differences are defined as $P<0.05$.

\section{RESULTS}

\section{Association of QSOX1 I2 $204 C>T$ and $I 2378 C>T$ with cattle carcass traits}

The PCR products of the QSOX1 second intron were subjected to RFLP analysis. Two polymorphisms were found in the PCR products (Fig. 1). Associations of $Q S O X 1$ polymorphisms with the carcass trait data were analyzed using one-way ANOVA with SPSS 19.0. The results showed that I2 $204 \mathrm{C}>\mathrm{T}$ was significantly associated with meat quality traits, including tare weight, hind hoof weight, kidney fat weight, marbling, loin thickness, fat coverage, back fat thickness, liver weight, and heart weight $(P<0.05)$. The tare weight, hind hoof weight, and marbling in genotype CC were higher than those in CT and TT; however, the kidney fat weight, fat coverage, and back fat thickness were higher in genotype TT, suggesting that TT might be the dominant genotype in lipid metabolism (Table 2).

Analysis showed that $\mathrm{I} 2378 \mathrm{C}>\mathrm{T}$ was also significantly correlated with carcass traits such as slaughter rate, hind hoof weight, kidney fat weight, genital fat, loin thickness, fat coverage, loin eye area, liver weight, and heart weight. In addition, kidney fat weight, loin eye area, and heart weight were higher in genotype CC, indicating that CC could potentially be used to select better meat qualities (Table 3).

\section{$m R N A$ expressions of QSOX1 in MECs and BFFs}

Given that the cell morphology and GFP expression in the MECs and BFFs of the two transfection groups were similar to those in the negative control at $24 \mathrm{hr}$ post transfection (Figs. 2 and 3), the transfected cells could be used for the subsequent experiments. The mRNA expression of QSOX1 in the MECs and BFFs transfected with Neo-QSOX1-bos-1667 was significantly lower than that in the cells with the negative control vector $(P<0.05$, Fig. 4A and 4B). Therefore, Neo-QSOX1-bos-1667 with the target sequence GCAACATCGTCCTAGACTTTC resulted in the most efficient interference and was chosen as the interference vector in subsequent experiments (Fig. 4).

Finally, the MECs and BFFs transfected with the overexpression vectors PBI-CMV3 and PBI-CMV3-QSOX1 had significantly higher mRNA expression levels than those transfected with the control vector $(P<0.01$, Fig. $4 \mathrm{C}$ and $4 \mathrm{D})$.

\section{Relative QSOX1 levels in MECs and BFFs}

The results of western blot showed that cells transfected with PBI-CMV3-QSOX1 had the highest protein levels and those with Neo-QSOX1-bos-1667 had the lowest protein levels when compared with those in the control group ( $P<0.05$, Fig. 5A and 5B).

\section{Triglycerides in MECs and BFFs}

Relative triglyceride levels in MECs and BFFs transfected with PBI-CMV3, PBI-CMV3-QSOX1, Neo-shNC, and Neo-QSOX1bos- 1667 were analyzed. The results showed that the relative content of triglycerides was extremely significantly increased in MECs and BFFs transfected with PBI-CMV3-QSOX1 ( $P<0.01$, Fig. 6A and 6B); however, there were no significant changes in the triglyceride levels of BFFs transfected with Neo-QSOX1-bos-1667 ( $P>0.05$, Fig. 6A). 


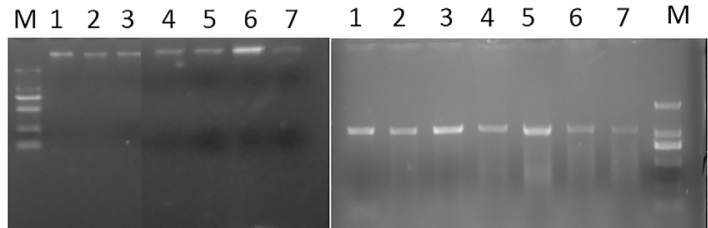

A

B

$\begin{array}{llllllllllllllll}M & 1 & 2 & 3 & 4 & 5 & 6 & 7 & M & 1 & 2 & 3 & 4 & 5 & 6 & 7\end{array}$

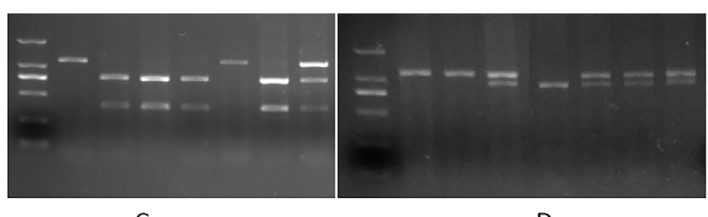

C

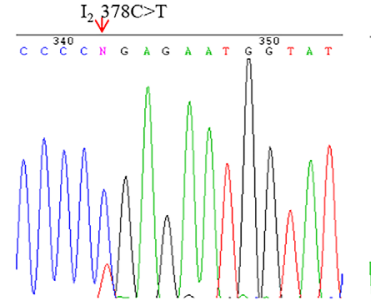

$\mathrm{E}$

E: I2 $378 \mathrm{C}>\mathrm{T}$ sequencing

F: I2 204C $>$ T sequencing

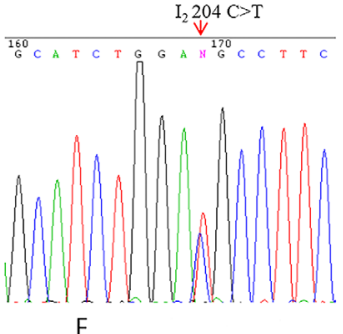

$\mathrm{F}$
A: genome DNA extraction
B: Target sequence of $Q S O X 1$ amplification
$\mathrm{C}$ : I2 $378 \mathrm{C}>\mathrm{T}$ genotyping
D: I2 204C $>$ T genotyping

Fig. 1. I2 204C $>\mathrm{T}$ and $\mathrm{I} 2378 \mathrm{C}>\mathrm{T}$ SNPs of $Q S O X 1$. SNPs of $\mathrm{I} 2204 \mathrm{C}>\mathrm{T}$ and $\mathrm{I} 2378 \mathrm{C}>\mathrm{T}$ were detected using restriction enzyme digestion and sequencing.

Table 2. Association between SNP I2-204 of $Q S O X I$ and certain cattle carcass traits

\begin{tabular}{|c|c|c|c|c|c|c|c|c|c|c|}
\hline $\begin{array}{l}\text { I2 204C > } \\
\text { T genotype }\end{array}$ & $\begin{array}{l}\text { Number of } \\
\text { individuals }\end{array}$ & $\begin{array}{l}\text { Tare weight } \\
(\mathrm{kg})\end{array}$ & $\begin{array}{l}\text { Hind hoof weight } \\
\qquad(\mathrm{kg})\end{array}$ & $\begin{array}{l}\text { Kidney fat weight } \\
(\mathrm{kg})\end{array}$ & $\begin{array}{l}\text { Marbling } \\
\left(\mathrm{cm}^{2}\right)\end{array}$ & $\begin{array}{l}\text { Loin thickness } \\
\qquad(\mathrm{cm})\end{array}$ & $\begin{array}{c}\text { Fat coverage } \\
(\%)\end{array}$ & $\begin{array}{l}\text { Back fat thickness } \\
(\mathrm{cm})\end{array}$ & $\begin{array}{l}\text { Liver weight } \\
(\mathrm{kg})\end{array}$ & $\begin{array}{l}\text { Heart weight } \\
\quad(\mathrm{kg})\end{array}$ \\
\hline $\mathrm{CC}$ & 165 & $43.7796 \pm 6.68483^{\mathrm{a})}$ & $3.6622 \pm 1.07676^{\mathrm{a})}$ & $4.0952 \pm 2.66823^{\mathrm{a})}$ & $5.5104 \pm 0.63237^{\mathrm{a})}$ & $6.7052 \pm 0.97175^{\mathrm{a})}$ & $44.1354 \pm 21.93657^{\mathrm{a})}$ & $0.8117 \pm 0.58281^{\mathrm{a})}$ & $5.6619 \pm 1.13863^{\mathrm{a})}$ & $1.7466 \pm 0.326^{\mathrm{a})}$ \\
\hline CT & 117 & $41.9694 \pm 5.92707^{\mathrm{b})}$ & $3.4674 \pm 1.01616^{\mathrm{b})}$ & $4.7811 \pm 2.703^{\mathrm{b})}$ & $5.3791 \pm 0.71641^{\mathrm{a}, \mathrm{b})}$ & $6.9542 \pm 0.89963^{b)}$ & $49.1699 \pm 20.56123^{b)}$ & $0.9907 \pm 0.62534^{b)}$ & $5.967 \pm 1.06934^{\mathrm{b})}$ & $1.8424 \pm 0.384^{b)}$ \\
\hline TT & 28 & $41.5489 \pm 6.05859^{\mathrm{b})}$ & $3.405 \pm 1.00288^{\mathrm{b}}$ & $4.9115 \pm 2.99249^{\mathrm{b})}$ & $5.3014 \pm 0.71729^{b)}$ & $6.8011 \pm 0.85138^{\mathrm{a}, \mathrm{b})}$ & $49.2822 \pm 21.83034^{b)}$ & $1.0492 \pm 0.6745^{\mathrm{b})}$ & $5.9848 \pm 1.15281^{\mathrm{b})}$ & $1.8141 \pm 0.325^{\mathrm{ab})}$ \\
\hline
\end{tabular}

Numbers with different superscripts $(\mathrm{a}, \mathrm{b})$ are significantly different $(P<0.05)$.

Table 3. Association between SNP I2-378 of QSOXI and certain cattle carcass traits

\begin{tabular}{|c|c|c|c|c|c|c|c|c|c|c|}
\hline $\begin{array}{l}\text { I2 378C > } \\
\text { T genotype }\end{array}$ & $\begin{array}{l}\text { Number of } \\
\text { individuals }\end{array}$ & $\begin{array}{c}\text { Slaughter rate } \\
(\%)\end{array}$ & $\begin{array}{l}\text { Hind hoof weight } \\
\qquad(\mathrm{kg})\end{array}$ & $\begin{array}{l}\text { Kidney fat weight } \\
(\mathrm{kg})\end{array}$ & $\begin{array}{l}\text { Genital fat } \\
(\mathrm{kg})\end{array}$ & $\begin{array}{l}\text { Loin thickness } \\
\qquad(\mathrm{cm})\end{array}$ & $\begin{array}{c}\text { Fat coverage } \\
(\%)\end{array}$ & $\begin{array}{l}\text { Loin eye area } \\
\qquad\left(\mathrm{cm}^{2}\right)\end{array}$ & $\begin{array}{l}\text { Liver weight } \\
(\mathrm{kg})\end{array}$ & $\begin{array}{l}\text { Heart weight } \\
(\mathrm{kg})\end{array}$ \\
\hline $\mathrm{CC}$ & 79 & $52.2616 \pm 2.34065^{\mathrm{a})}$ & & $4.7127 \pm 2.8092^{\mathrm{a})}$ & & $027^{\text {a) }}$ & $713+20$ & $80.0157 \pm 12.482^{\mathrm{a}}$ & $5.9148 \pm 1.09353^{\mathrm{a})}$ & 8105 \\
\hline CT & & & $3.4694 \pm 0.9794^{\text {a) }}$ & $4.6801 \pm 2.7354^{\mathrm{a})}$ & $0.9487 \pm 0.34243^{\mathrm{b})}$ & & $48.7955 \pm 21.5405^{\mathrm{a})}$ & $78.9223 \pm 13.443^{\mathrm{a}, \mathrm{b}} \mathrm{s}$ & $5.9272 \pm 1.09847^{\mathrm{a}}$ & $32039^{\mathrm{a}}$ \\
\hline TT & 89 & $51.322 \pm 3.01939^{\mathrm{b})}$ & $3.7953 \pm 1.0365^{\mathrm{b})}$ & $3.897 \pm 2.92718^{\mathrm{b})}$ & $0.895 \pm 0.31726^{a, b)}$ & $6.5233 \pm 0.8811^{\mathrm{b})}$ & $43.8 \pm 25.81553^{b)}$ & $74.9117 \pm 12.5183^{b)}$ & $5.548 \pm 1.32602^{b)}$ & $1.6927 \pm 0.37619^{b)}$ \\
\hline
\end{tabular}

Numbers with different superscripts $(\mathrm{a}, \mathrm{b})$ are significantly different $(P<0.05)$.

\section{Cell apoptosis rate}

Cells apoptosis was analyzed using flow cytometry. The higher apoptosis rate in MECs might be related to their inherent viability. Nevertheless, both BFFs and MECs with QSOX1 overexpression had lower apoptosis rates than those with interference genes, suggesting that QSOX1 suppresses apoptosis in both types of cells (Fig. 7).

\section{DISCUSSION}

QSOX1 is expressed in various cells with different functions. In pancreatic and renal cancer cell lines, the overexpression of QSOX1 could effectively reduce tumor cell migration [11]. QSOX1 knockdown inhibits vascular smooth muscle cell migration and proliferation and promotes the neointimal thickening of the rat carotid artery [4]. In fibroblasts and mesenchymal stem cells, QSOX1 functions as an immune response modifier to prevent tissue inflammation and fibrosis in the lungs [17]. QSOX1 might also be involved in the differentiation and regression of neuroblastomas through extracellular maturation and apoptosis induction [2]. It is suggested that $Q S O X 1$ could be a potential biomarker for acute decompensated heart failure [9]. QSOX1 also has important regulatory functions in human lung fibroblasts, guinea pig endometrial cells, and rat seminal vesicle cells [5]. In the present study, BFFs and MECs transfected with the QSOX1 overexpression vector PBI-CMV3-QSOX1 showed reduced apoptosis rates and increased triglyceride levels. In BFFs, the apoptosis rate in cells transfected with PBI-CMV3-QSOX1 (8.5\%) was significantly lower than that in cells transfected with Neo-QSOX1-bos-1667 (19.32\%), and QSOX1 expression mainly affected apoptosis in late- 

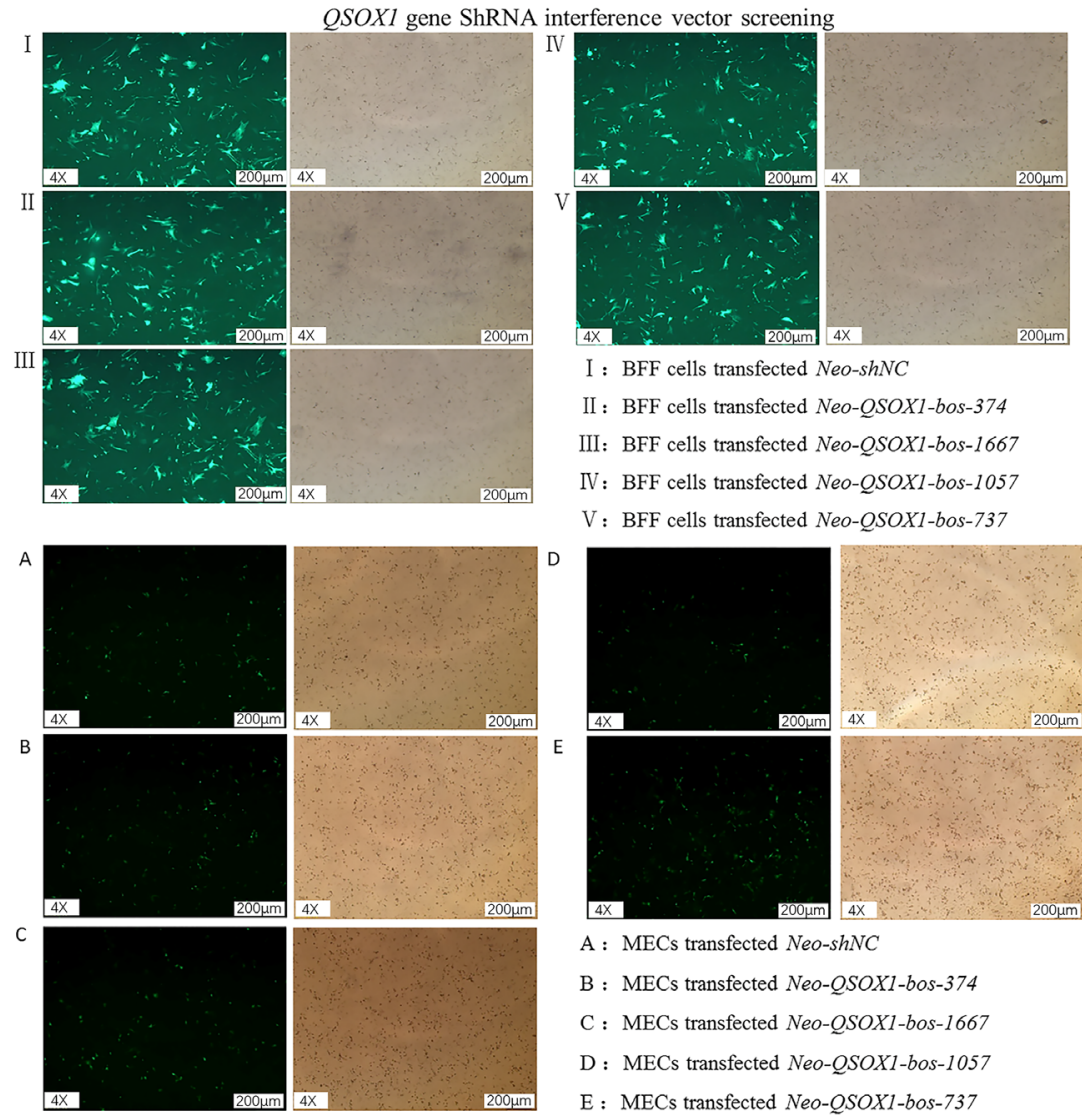

I : BFF cells transfected Neo-shNC

II : BFF cells transfected Neo-QSOX1-bos-374

III: BFF cells transfected Neo-QSOX1-bos- 1667

IV: BFF cells transfected Neo-QSOXI-bos- 1057

$\mathrm{V}$ : BFF cells transfected Neo-QSOX1-bos-737

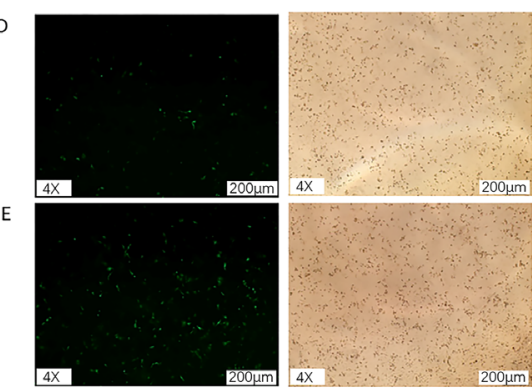

A : MECs transfected Neo-shNC

B : MECs transfected Neo-QSOXI-bos-374

C : MECs transfected Neo-QSOXI-bos-1667

D : MECs transfected Neo-QSOXI-bos-1057

E : MECs transfected Neo-QSOX1-bos-737 cells transfected QSOX1 interference and overecpression vetor

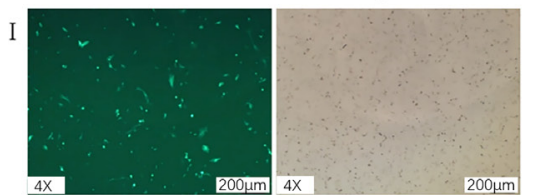

II
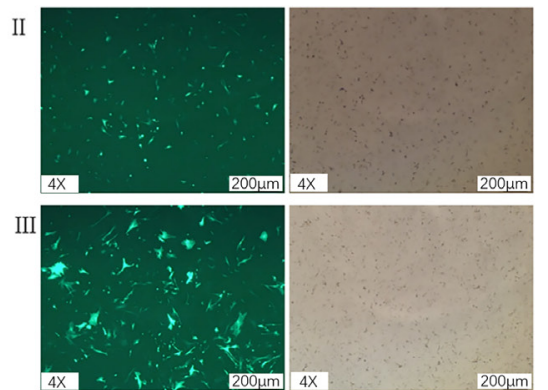

A
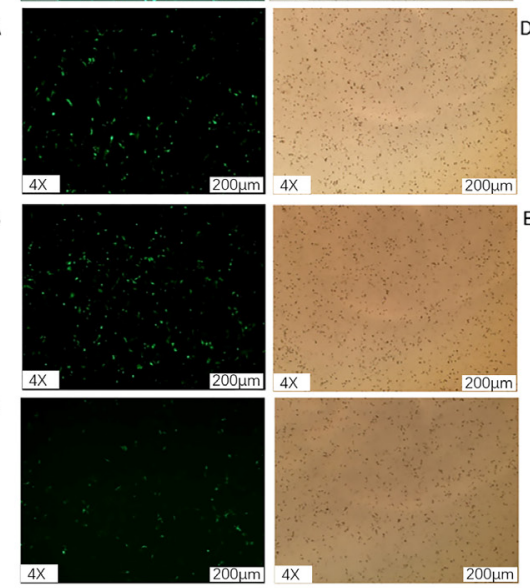
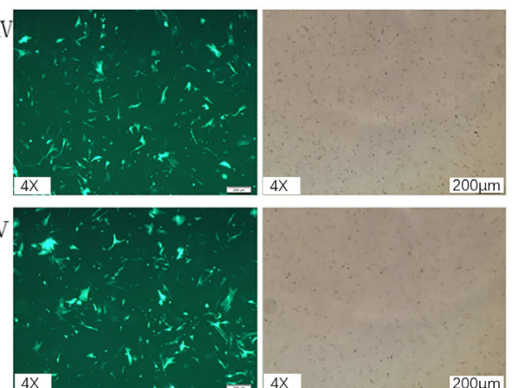

I : BFF cells transfected $P B I-C M V 3$

II : BFF cells transfected $P B I-C M V 3-Q S O X I$

III: BFF cells transfected Neo-shNC

IV: BFF cells transfected Neo-QSOXI-bos-737

V: BFF cells transfected Neo-QSOXI-bos-1667
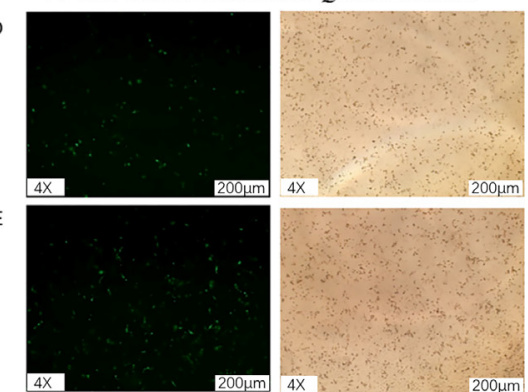

A : MEC cells transfected $P B I-C M V 3$

B : MEC cells transfected $P B I-C M V 3-Q S O X I$

$\mathrm{C}:$ MEC cells transfected $\mathrm{NeO}-\mathrm{ShNC}$

D : MEC cells transfected Neo-QSOX1-bos-737

E : MEC cells transfected Neo-QSOXI-bos-1667
Fig. 2. Efficiency screening for the silencing vectors of $Q S O X 1$. BFFs and MECs were transfected with Neo-shNC, Neo-OSOX1bos-374, Neo-QSOX1-bos-1667, Neo-QSOX1bos-1057 and Neo-QSOX1-bos-737 to screen for the most effective $Q S O X 1$ silencing vector.
Fig. 3. Cells transfected with $Q S O X 1$ silencing and overexpression vectors. BFFs and MECs were transfected with $Q S O X 1$ silencing and overexpression vectors, including $P B I-C M V 3$, PBI-CMV3-QSOX1, Neo-shNC and NeoQSOX1-bos-1667. 
Relative expression of $Q S O X 1 \mathrm{mRNA}$ in BFF cells and MECs

A

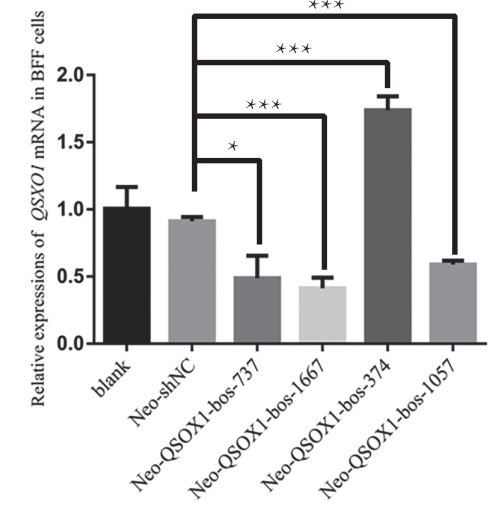

C

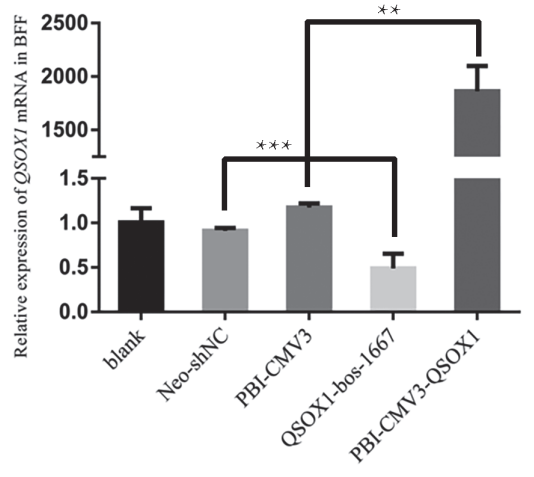

B

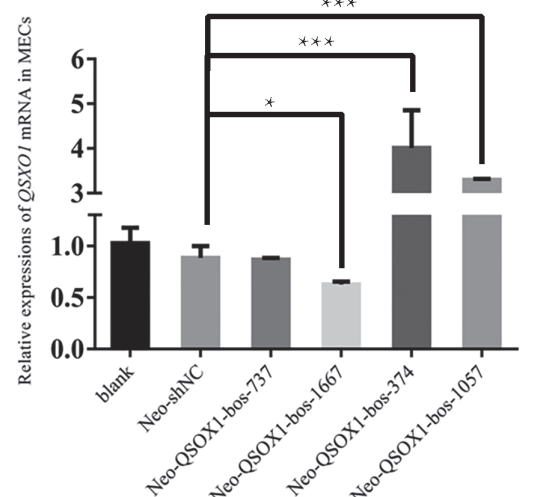

D

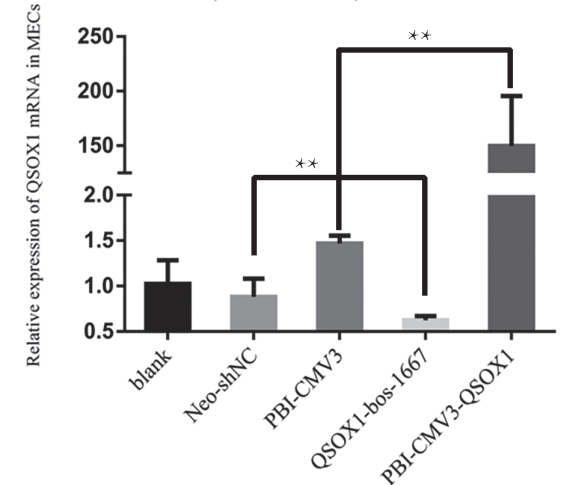

Fig. 4. Relative expressions of QSOX1 mRNA in BFFs and MECs. A and B: QSOX1 mRNA expressions in BFFs and MECs transfected with the interference vectors Neo-shNC, Neo-QSOX1-bos-374, Neo-QSOX1-bos-1667, Neo-QSOX1-bos-1057 and Neo-QSOX1-bos-737. C and D: cells transfected with the interference vector QSOX1-bos-1667 with control vector Neo-shNC and the overexpression vector $P B I-C M V 3-Q S O X 1$ with control vector $P B I-C M V 3$; the test was repeated 3 times $(* P<0.05, * * P<0.01$ and $* * * P<0.001)$.

Protein expression of $Q S O X 1$ in BFF cells and MECs

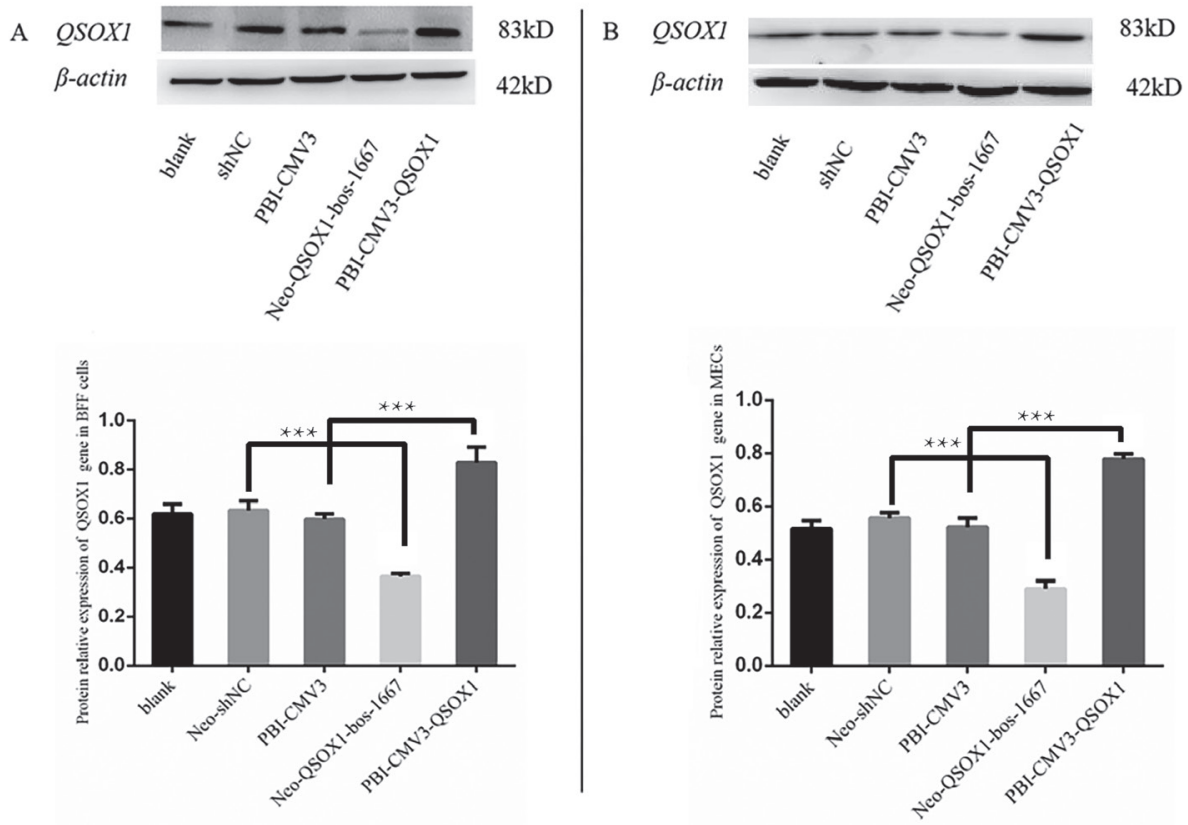

Fig. 5. QSOX1 levels in BFFs and MECs. A: Relative QSOX1 levels in BFFs. B: MECs transfected with blank, Neo-shNC, PBICMV3, Neo-QSOX1-bos-1667 and PBI-CMV3-QSOX1; the test was repeated 3 times $(* * * P<0.001)$. 

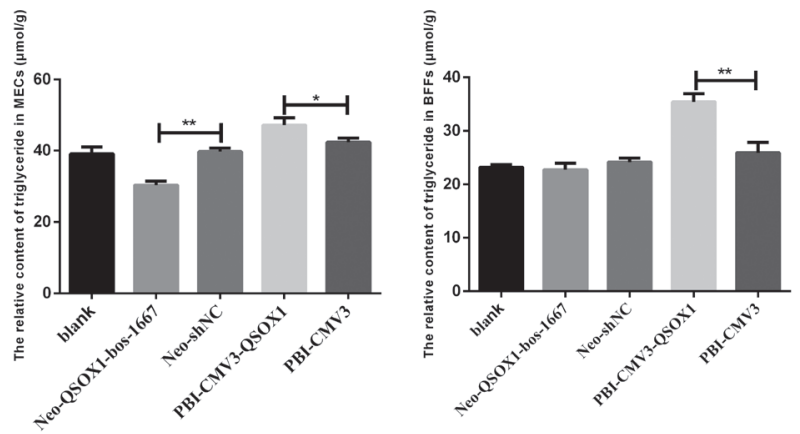

Fig. 6. Relative triglyceride levels in BFFs and MECs. A: BFFs transfected with blank, Neo-shNC, PBI-CMV3, Neo-QSOXI-bos-1667 and $P B I-C M V 3-Q S O X 1$. B: MECs transfected with the same vectors as in (A); the test was repeated 3 times $\left(* P<0.05,{ }^{* *} P<0.01\right)$.
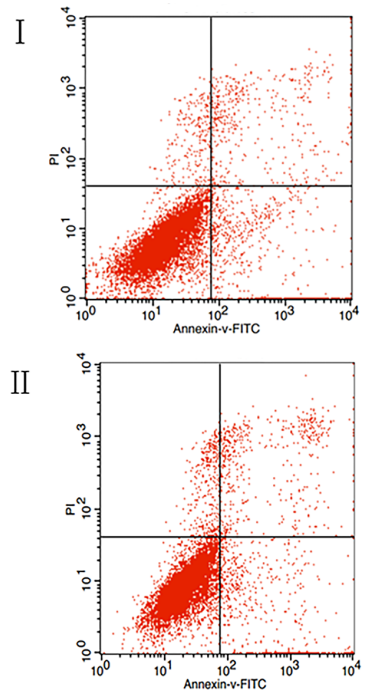

I : BFF cells transfected Neo-shNC

II : BFF cells transfected PBI-CMV3

A

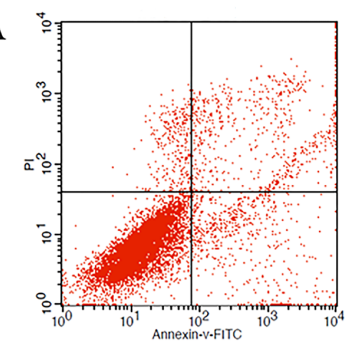

B

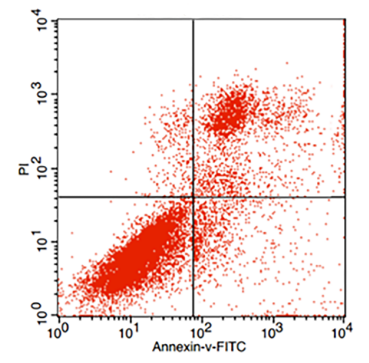

III Acquisition Date: 30 -Mar-16 X Parameter: Annexin-v-FITC (Log) Quad Location: 76,40 Quad Events \% Gated \% Total $\begin{array}{rrrr}\text { UR } & 217 & 2.17 & 1.99 \\ 439 & 4.39 & 4.03\end{array}$ $\begin{array}{rrrr}\text { UR } & 439 & 4.39 & 4.03 \\ \text { LL } & 8656 & 86.56 & 79.54 \\ \text { LR } & 688 & 6.88 & 6.32\end{array}$

Acquisition Date: 30-Mar-16 Gated Events: 10000 X Parameter: Annexin-v-FITC (Log) Quad Location: 76,40

Quad Events \% Gated \% Total $\begin{array}{rrrr}\text { UL } & 331 & 3.31 & 3.06 \\ \text { UR } & 503 & 5.03 & 4.65 \\ \text { LL } & 8517 & 85.17 & 78.66 \\ \text { LR } & 649 & 6.49 & 5.99\end{array}$

Acquisition Date: 30-Mar-16 Gated Events: 10000 X Parameter: Annexin-v-FITC (Log) Quad Location: 76, 40 Quad Events \% Gated \% Total $\begin{array}{rrrr}\text { UL } & 283 & 2.83 & 2.65 \\ \text { UR } & 649 & 6.49 & 6.07 \\ \text { U } & 8487 & 84.87 & 79.43\end{array}$ $\begin{array}{rrrr}\text { LL } & 8487 & 84.87 & 79.43 \\ \text { LR } & 581 & 5.81 & 5.44\end{array}$

Acquisition Date: 30-Mar-16 Gated Events: 10000 X Parameter: Annexin-v-FITC (Log) Quad Location: 76, 40

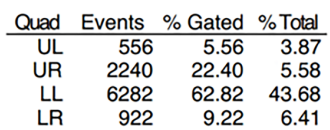

IV
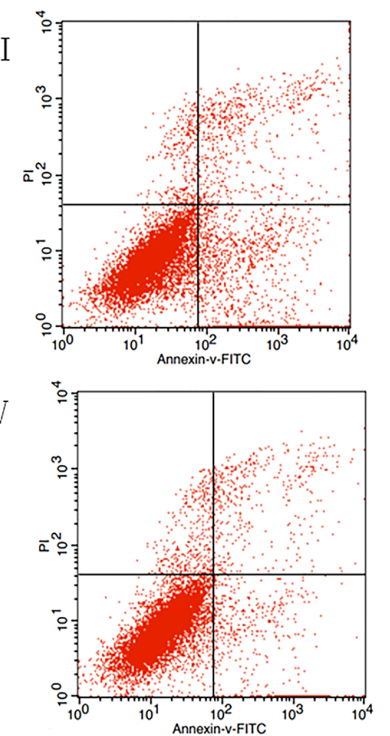

Acquisition Date: 30-Mar-16 Gated Events: 10000

X Parameter: Annexin-v-FITC (Log) Quad Location: 76, 40

\begin{tabular}{|c|c|c|c|}
\hline Quad & Events & $\%$ Gated & $\%$ Total \\
\hline UL & 355 & 3.55 & 3.30 \\
\hline UR & 402 & 4.02 & 3.73 \\
\hline LL & 8729 & 87.29 & 81.06 \\
\hline LR & 514 & 5.14 & 4.77 \\
\hline
\end{tabular}

III: BFF cells transfected Neo-QSOX1-bos-1667

IV : BFF cells transfected PBI-CMV3-QSOX1

$\mathrm{C}$

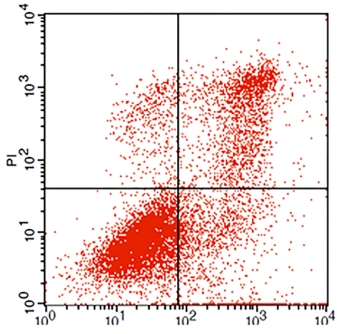

$\mathrm{D}$

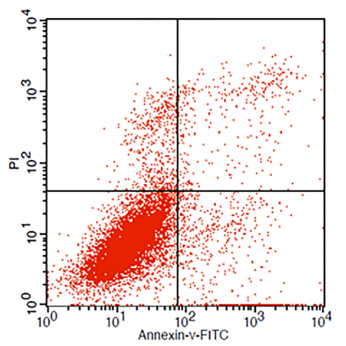

Acquisition Date: 30-Mar-16 Gated Events: 10000 $X$ Parameter: Annexin-v-FITC (Log) Quad Location: 76, 40

\begin{tabular}{rrrr} 
Quad & Events & $\%$ Gated & $\%$ Total \\
\hline UL & 467 & 4.67 & 4.04 \\
UR & 2021 & 20.21 & 17.47 \\
LL & 5986 & 59.86 & 51.75 \\
LR & 1526 & 15.26 & 13.19
\end{tabular}

Acquisition Date: 30-Mar-16 Gated Events: 10000 $X$ Parameter: Annexin-v-FITC (Log) Quad Location: 76, 40

Quad Events \% Gated \% Total
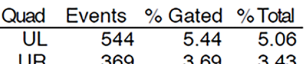

$\begin{array}{llrr}\text { LL } & 8462 & 84.62 & 78.75\end{array}$
A : MEC cells transfected Neo-shNC
C: MEC cells transfected Neo-QSOX1-bos-1667
B : MEC cells transfected PBI-CMV3
D: MEC cells transfected PBI-CMV3-QSOX1

Fig. 7. Apoptosis rates in BFFs and MECs. Apoptosis rates of BFFs and MECs transfected with blank, Neo-shNC, PBI-CMV3, Neo-QSOX1-bos-1667 and PBI-CMV3-QSOX1 were analyzed using flow cytometry. 
stage cells. In cattle MECs, the PBI-CMV3-QSOX1 group (9.25\%) had a significantly lower apoptosis rate than the Neo-QSOX1bos-1667 group (30.66\%) did.

There was a significant correlation between SNPs of QSOX1 and meat quality traits. Studies have shown that SNPs in introns have a great impact on gene functions. In this study, genotype CC in I2 $204 \mathrm{C}>\mathrm{T}$ mainly affected the tare weight, hind hoof weight, and marbling, whereas TT in I2 $204 \mathrm{C}>\mathrm{T}$ might be the dominant genotype in lipid metabolism, suggesting that TT in I2 $204 \mathrm{C}>\mathrm{T}$ could be a marker for better meat qualities. Genotype CC in $\mathrm{I} 2378 \mathrm{C}>\mathrm{T}$ mainly impacted the kidney fat weight and heart weight, suggesting that $\mathrm{CC}$ could be a marker for visceral disorders such as cardiac hypertrophy and renal lipoma.

Based on the effects of $Q S O X 1$ on cell apoptosis and triglyceride production in cattle MECs and BFFs and the correlation of the gene's SNPs with certain meat quality traits, we recommend that $Q S O X 1$ be considered as a key gene for in cattle genetics and breeding. In conclusion, QSOX1 SNPs were significantly correlated with meat quality and played an important role in lipid metabolism and cell apoptosis, suggesting that $Q S O X 1$ could potentially be used as a biomarker in cattle breeding for better meat quality.

CONFLICT OF INTEREST. The authors declare no conflict of interest.

ACKNOWLEDGMENTS. This work was supported by the National R\&D Project of Transgenic Organisms of the Ministry of Science and Technology of China (2016ZX08009003-006), National Natural Science Foundation of China (no. 31372278), National High Technology Research and Development Program (863 Program, no.2013AA102505), and Jilin Province Industrial Technology Research and Development Program (2016C032).

\section{REFERENCES}

1. Abskharon, R. N., Ramboarina, S., El Hassan, H., Gad, W., Apostol, M. I., Giachin, G., Legname, G., Steyaert, J., Messens, J., Soror, S. H. and Wohlkonig, A. 2012. A novel expression system for production of soluble prion proteins in E. coli. Microb. Cell Fact. 11: 6. [Medline] [CrossRef]

2. Araújo, D. G., Nakao, L., Gozzo, P., Souza, C. D., Balderrama, V., Gugelmin, E. S., Kuczynski, A. P., Olandoski, M. and de Noronha, L. 2014. Expression level of quiescin sulfhydryl oxidase 1 (QSOX1) in neuroblastomas. Eur. J. Histochem. 58: 2228. [Medline] [CrossRef]

3. Bass, J. J., Wilkinson, D. J., Rankin, D., Phillips, B. E., Szewczyk, N. J., Smith, K. and Atherton, P. J. 2016. An overview of technical considerations for Western blotting applications to physiological research. Scand. J. Med. Sci. Sports. 27: 4-25. [Medline]

4. Borges, B. E., Appel, M. H., Cofré, A. R., Prado, M. L., Steclan, C. A., Esnard, F., Zanata, S. M., Laurindo, F. R. and Nakao, L. S. 2015. The flavooxidase QSOX1 supports vascular smooth muscle cell migration and proliferation: Evidence for a role in neointima growth. Biochim. Biophys. Acta 1852: 1334-1346. [Medline] [CrossRef]

5. Chakravarthi, S., Jessop, C. E., Willer, M., Stirling, C. J. and Bulleid, N. J. 2007. Intracellular catalysis of disulfide bond formation by the human sulfhydryl oxidase, QSOX1. Biochem. J. 404: 403-411. [Medline] [CrossRef]

6. Coppock, D. L., Cina-Poppe, D. and Gilleran, S. 1998. The quiescin Q6 gene (QSCN6) is a fusion of two ancient gene families: thioredoxin and ERV1. Genomics 54: 460-468. [Medline] [CrossRef]

7. da Silva, J. M., Giachetto, P. F., da Silva, L. O., Cintra, L. C., Paiva, S. R., Yamagishi, M. E. and Caetano, A. R. 2016. Genome-wide copy number variation $(\mathrm{CNV})$ detection in Nelore cattle reveals highly frequent variants in genome regions harboring QTLs affecting production traits. $B M C$ Genomics 17: 454. [Medline] [CrossRef]

8. Das, P., Siegers, G. M. and Postovit, L. M. 2013. Illuminating luminal B: QSOX1 as a subtype-specific biomarker. Breast Cancer Res. 15 : 104. [Medline] [CrossRef]

9. Doehner, W. 2012. Diagnostic biomarkers in cardiovascular disease: the proteomics approach. Eur. Heart J. 33: 2249-2251. [Medline] [CrossRef]

10. Fang, X. B., Zhang, L. P., Yu, X. Z., Li, J. Y., Lu, C. Y., Zhao, Z. H. and Yang, R. J. 2014. Association of HSL gene E1-c.276 C>T and E8-c.51 C>T mutation with economical traits of Chinese Simmental cattle. Mol. Biol. Rep. 41: 105-112. [Medline] [CrossRef]

11. Hanavan, P. D., Borges, C. R., Katchman, B. A., Faigel, D. O., Ho, T. H., Ma, C. T., Sergienko, E. A., Meurice, N., Petit, J. L. and Lake, D. F. 2015. Ebselen inhibits QSOX1 enzymatic activity and suppresses invasion of pancreatic and renal cancer cell lines. Oncotarget 6: 18418-18428. [Medline] [CrossRef]

12. Israel, B. A., Jiang, L., Gannon, S. A. and Thorpe, C. 2014. Disulfide bond generation in mammalian blood serum: detection and purification of quiescin-sulfhydryl oxidase. Free Radic. Biol. Med. 69: 129-135. [Medline] [CrossRef]

13. Lange, H., Lisowsky, T., Gerber, J., Mühlenhoff, U., Kispal, G. and Lill, R. 2001. An essential function of the mitochondrial sulfhydryl oxidase Ervlp/ALR in the maturation of cytosolic Fe/S proteins. EMBO Rep. 2: 715-720. [Medline] [CrossRef]

14. Saben, J., Zhong, Y., McKelvey, S., Dajani, N. K., Andres, A., Badger, T. M., Gomez-Acevedo, H. and Shankar, K. 2014. A comprehensive analysis of the human placenta transcriptome. Placenta 35: 125-131. [Medline] [CrossRef]

15. Shi, C. Y., Fan, Y., Liu, B. and Lou, W. H. 2013. HIF1 contributes to hypoxia-induced pancreatic cancer cells invasion via promoting QSOX1 expression. Cell. Physiol. Biochem. 32: 561-568. [Medline] [CrossRef]

16. Sobral, A. C., Neto, V. M., Traiano, G., Percicote, A. P., Gugelmin, E. S., de Souza, C. M., Nakao, L., Torres, L. F. and de Noronha, L. 2015. Immunohistochemical expression of sulfhydryl oxidase (QSOX1) in pediatric medulloblastomas. Diagn. Pathol. 10: 37. [Medline] [CrossRef]

17. Sun, X., Zheng, M., Zhang, M., Qian, M., Zheng, Y., Li, M., Cretoiu, D., Chen, C., Chen, L., Popescu, L. M. and Wang, X. 2014. Differences in the expression of chromosome 1 genes between lung telocytes and other cells: mesenchymal stem cells, fibroblasts, alveolar type II cells, airway epithelial cells and lymphocytes. J. Cell. Mol. Med. 18: 801-810. [Medline] [CrossRef]

18. Tian, J., Zhao, Z., Zhang, L., Zhang, Q., Yu, Z., Li, J. and Yang, R. 2013. Association of the leptin gene E2-169T >C and E3-299T >A mutations with carcass and meat quality traits of the Chinese Simmental-cross steers. Gene 518: 443-448. [Medline] [CrossRef]

19. Zhang, X., Li, C., Liu, X., Lu, C., Bai, C., Zhao, Z. and Sun, B. 2015. Differential expression of miR-499 and validation of predicted target genes in the testicular tissue of swine at different developmental stages. DNA Cell Biol. 34: 464-469. [Medline] [CrossRef]

20. Zheng, W., Chu, Y., Yin, Q., Xu, L., Yang, C., Zhang, W., Tang, Y. and Yang, Y. 2011. Crucial effect of the first CXXC motif of human QSOX 1b on the activity to different substrates. J. Biochem. 149: 293-300. [Medline] [CrossRef] 